Fixed Point Theory, 20(2019), No. 1, 107-112

DOI: $10.24193 /$ fpt-ro.2019.1.06

http://www.math.ubbcluj.ro/ nodeacj/sfptcj.html

\title{
A NOTE ON EXISTENCE AND UNIQUENESS FOR INTEGRAL EQUATIONS WITH SUM OF TWO OPERATORS: PROGRESSIVE CONTRACTIONS
}

\author{
T.A. BURTON \\ Northwest Research Institute, 732 Caroline St., Port Angeles, WA, 98362 USA \\ E-mail: taburton@olypen.com
}

\begin{abstract}
In this note we show a simple way to obtain a unique solution on $[0, \infty)$ of a scalar integral equation

$$
x(t)=g(t, x(t))+\int_{0}^{t} A(t-s) f(s, x(s)) d s
$$

where $x, y \in \Re$ and $t \geq 0$ imply that $|g(t, x)-g(t, y)| \leq \alpha|x-y|, 0<\alpha<1$, and for each $E>0$ there is a $K>0$ so that $x, y \in \Re$ and $0 \leq t \leq E$ imply $|f(t, x)-f(t, y)| \leq K|x-y|$. We introduce a progressive contraction. The constant $K$ is a function of $E$ and, hence, may tend to infinity as $E \rightarrow \infty$. The conclusion is that there is a single function $\xi(t)$ satisfying the equation on $[0, \infty)$ without resorting to any of the classical translations and extensions of solutions which, in fact, must invoke Zorn's Lemma and which can encounter difficulties as $K \rightarrow \infty$.

Key Words and Phrases: Progressive contractions, integral equations, existence, uniqueness, fixed points.
\end{abstract}

2010 Mathematics Subject Classification: 45D05, 45G05, 47H09, 47H10.

\section{REFERENCES}

[1] T.A. Burton, Stability and Periodic Solutions of Ordinary and Functional Differential Equations, Academic Press, Orlando, 1985.

[2] L.E. El'sgol'ts, Introduction to the Theory of Differential Equations with Deviating Arguments, Holden-Day, San Francisco, 1966.

[3] J. Hale, Theory of Functional Differential Equations, Springer, New York, 1977.

[4] R.K. Miller, Nonlinear Volterra Integral Equations, Benjamin, Menlo Park, CA, 1971.

[5] D.R. Smart, Fixed Point Theorems, Cambridge, 1980.

Received: August 10, 2016; Accepted: October 13, 2016. 
T.A. BURTON 